\title{
Severe chronic cough after Lap-Band gastric surgery
}

\author{
Jacqueline Nemni BEng MD FRCPC FCCP Diplom ABSM
}

\author{
J Nemni. Severe chronic cough after Lap-Band gastric surgery. \\ Can Respir J 2007;14(3):171-172.
}

\begin{abstract}
Respirologists are often consulted in cases of chronic cough. Most patients have diagnoses of asthma, upper airway cough or gastroesophageal reflux disease. The present case describes a newly recognized cause of a cough in a patient who had undergone laparoscopic adjustable gastric banding for weight loss. The cough was persistent and severe for several months, and did not respond to any therapeutic interventions. Imaging studies were not helpful in making the diagnosis, which was confirmed by deflating the Lap-Band, thereby eliminating the cough.

As more patients undergo bariatric surgery, physicians must anticipate and be familiar with potential complications.
\end{abstract}

Key Words: Bariatric surgery; Chronic cough; Lap-Band surgery

\section{Une toux chronique grave après une chirurgie gastrique Lap-Band}

On consulte souvent des pneumologues en cas de toux chronique. La plupart des patients reçoivent des diagnostics d'asthme, de toux des voies supérieures ou de reflux gastro-œsophagien pathologique. Le présent cas décrit une nouvelle cause de toux chez une patiente qui avait subi un cerclage gastrique laparoscopique rajustable pour perdre du poids. La toux était persistante et grave depuis plusieurs mois et ne réagissait à aucune intervention thérapeutique. Les études d'imagerie n'ont pas contribué à poser le diagnostic, qui a été confirmé lorsque le dégonflage du dispositif Lap-Band a éliminé la toux.

Puisque de plus en plus de patients subissent une chirurgie bariatrique, on prévoit que plus de patients présentent des complications après l'intervention. Il faut donc se familiariser avec ces complications.
A s the incidence of obesity increases in our society, so will the number of treatment options. More and more patients are turning to bariatric surgery to help them in their battle against obesity. These patients have often tried a long series of diets and have used various medications to curb their appetite with little or only temporary success. Surgery is often a last resort, and an expensive one at that. Surgery has received growing media attention as a viable option for treatment of obesity, with many celebrities undergoing a procedure and then going on daytime television to talk about it.

Although some patients who obtain bariatric surgery are covered by the government or by private plans, the waiting list is often extremely long. Many patients end up paying privately for the surgery, which can cost thousands of dollars. A popular avenue of information for patients wanting to learn about the procedures is through the Internet or by word of mouth. Little is known about the pulmonary effects of such procedures; however, the patients are often willing to undergo the procedure regardless of any potential side effects. Most of the procedures are performed outside of the hospitals and therefore, respirologists may have little or no interaction with the surgeons and the patients, preoperatively or postoperatively.

\section{CASE PRESENTATION}

The case of a 54-year-old female teacher, who was born in Canada, is described. She had no pets at home, and had a family history of hyperlipidemia and asthma in her siblings. Her past medical history was notable for noninsulin-dependent diabetes, hypertension and hypothyroidism. There was an unconfirmed previous diagnosis of asthma or bronchitis requiring antibiotics approximately once a year. Her surgical history included a hysterectomy, a cholecystectomy and a gastric banding procedure performed in July 2003.

Gastric banding is performed laparoscopically. A doughnutshaped ring is placed at the junction of the esophagus and the stomach, below the diaphragm. This ring can be adjusted percutaneously, ie, inflated or deflated as needed according to the results obtained. The stomach itself is untouched. By delaying the passage of food into the stomach, the patients must eat less and more slowly, otherwise they will suffer unpleasant side effects, including pain and vomiting. The procedure is generally not covered by the government or by private plans. In the present patient, the cost of the procedure was $\$ 15,000$.

At the time of her first assessment by a respirologist in November 2004, her medications included thyroxine, metformin, atenolol, lisinopril and esomeprazole, with hydrocodone cough syrup and salbutamol taken as needed. She had also been given ipratropium nasal spray. She was a lifelong nonsmoker and did not drink alcohol.

She started complaining of a cough around March 2004. She went to her family physician as well as to Urgent Care, a walk-in clinic in Cambridge, Ontario, and received several courses of antibiotics without improvement. The cough was worse at night and she would describe abundant liquid mucous emanating from her right nostril, sometimes to the point of having to get up at night to change her bed sheets and clothes. After several weeks of intense coughing, she reported some hemoptysis. She denied any fever or chills, and a chest 
radiograph was reported as normal. Since her gastric surgery, she had reported a weight loss of approximately $27 \mathrm{~kg}$ and was still losing weight at the rate of approximately $1 \mathrm{~kg}$ per month. A Mantoux test was performed at Urgent Care, which was negative. A sinus radiograph was interpreted as showing a large polyp in the right maxillary sinus.

She was referred by Urgent Care to an ear, nose and throat surgeon. He noted some irritation of the posterior pharynx, which he suspected was due to reflux, and started the patient on esomeprazole. Direct visualization of the sinuses did not reveal the presence of any polyps, and the right maxillary sinus was normal.

She reported no further hemoptysis after starting the esomeprazole, but no improvement in the cough occurred. Salbutamol did not offer her any relief, nor did the hydrocodone cough syrup or the ipratropium nasal spray.

Immediately after her gastric surgery, she had reported difficulty in swallowing and often had to vomit after eating. This had resolved on adjustment of the pressure in the Lap-Band. The Lap-Band was adjusted regularly after the surgery, and according to her bariatric surgeon, it was functioning ideally with normal swallowing at the time she was seen for her cough.

She had been referred for urgent assessment because of the hemoptysis, but, in fact, was unable to come in for consultation for several months because of her own busy schedule and multiple doctors' appointments. She was not particularly worried about the issue because she felt well and was convinced that the small amount of bleeding had only occurred as a result of intense coughing. In fact, she felt that there was, all together, too much concern about her situation and that she just wanted to be rid of the cough and, in particular, the mucous at nighttime. She did not want to undergo invasive testing unless there was a compelling reason to do so.

On physical examination, she looked well and appeared to be in no distress. Physical examination was entirely normal. Spirometry revealed a slight reduction in forced expiratory volume in $1 \mathrm{~s}$ at $1.93 \mathrm{~L}$ (72\% of predicted) and a forced vital capacity at $2.26 \mathrm{~L}$ ( $66 \%$ of predicted), with normal saturation and no improvement with bronchodilator. Allergy testing was negative.

Further investigations were performed including a methacholine challenge test, which was normal, and full pulmonary function tests, which were also normal.

She was asked to discontinue the use of lisinopril and atenolol in the event that they were contributing to the cough. She was given nasal steroid spray to try to reduce the rhinorrhea. She was also seen by an internist who placed her on candesartan and hydrochlorothiazide for her hypertension, and also suggested a trial of fluticasone and domperidone for the cough. None of these medication changes made any difference to the cough.

On follow-up, it continued to be apparent that the cough was predominantly nocturnal and that it may be related to the gastric banding procedure. The patient was extremely reluctant to have the Lap-Band deflated because it had been effective in allowing her to lose weight and was worried that even a temporary reversal of the surgery would make her regain some of the weight. However, because it was clear that none of the treatments were helping, she consented to have it deflated. She went back to her surgeon and the Lap-Band was deflated as much as possible. This intervention resulted in the immediate disappearance of her cough and mucous.

\section{DISCUSSION}

Bariatric surgery is becoming much more common and will likely continue to increase as the incidence of obesity in our society rises. Patients who undergo surgery, particularly if they have paid thousands of dollars for it, may be less likely to complain of any problems because they are generally desperate for positive results. Procedures not funded by the government are often performed in private clinics, and are not well known to other physicians.

Two cases of chronic cough associated with bariatric surgery were reported by Gentil et al (1). In these cases, they also found severe esophageal dilation. In essence, the patients had developed signs of severe extrinsic obstruction of the distal esophagus. This is understandable if the Lap-Band is kept too inflated and not adequately assessed and adjusted.

In the present case, the esophagus appeared normal on a barium swallow. However, it seems quite likely that abnormalities would eventually develop. The esophagus in these patients should have normal contractility before the extrinsic obstruction is placed around it. It seems logical that the esophagus would increase the strength of contractions to overcome the obstruction. If this persists, dilation or hypertrophy of the distal portion of the esophagus could follow. The increased contractility may also cause reflux of the esophageal contents. During sleep, when swallowing is reduced and the patient is supine, this could result in reflux of saliva and upper airway secretions. I believe that this was the cause of the patient's cough. The exact pathophysiology of the cough is unclear but likely represents a delay in clearing of normal upper airway secretions from the esophagus, particularly while supine. It is unclear why she no longer had any complaints about delayed passage of food or fluid boluses. Reflux therapy was unhelpful because there was no evidence of gastric contents refluxing into the esophagus.

There have also been reports published by the same French group of pneumonia in patients post gastric banding surgery. This is also in keeping with a reflux-type pathology.

For respirologists who see patients with chronic coughs on a regular basis, the present case illustrates a new cause to consider that does not respond to any of our usual treatments.

\section{CONCLUSION}

There are many different causes of chronic coughs, most of which can be diagnosed and treated by respirologists. The present case illustrates that chronic cough may develop as a result of gastric banding surgery and does not appear to be relieved by any medical therapy, nor is it demonstrated on usual imaging. In cases of a refractory cough in patients who have undergone laparoscopic adjustable gastric banding, a therapeutic trial of deflating the Lap-Band may be required to determine if it is responsible for the cough.

\section{REFERENCES}

1. Gentil B, Etienne-Mastroianni B, Cordier JF. [Chronic cough after laparoscopic adjustable gastric banding.] Rev Mal Respir 2003;20:451-4. 


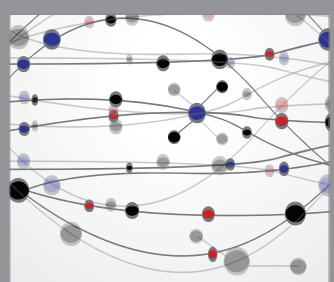

The Scientific World Journal
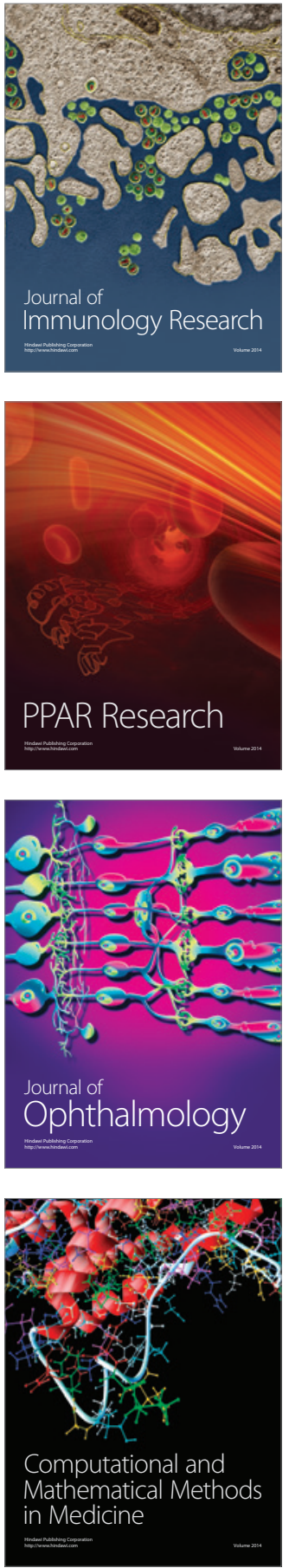

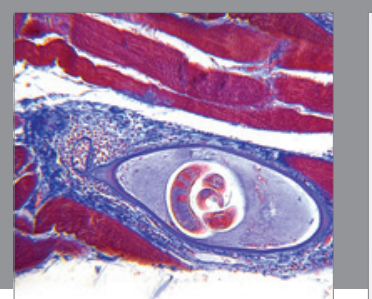

Gastroenterology Research and Practice

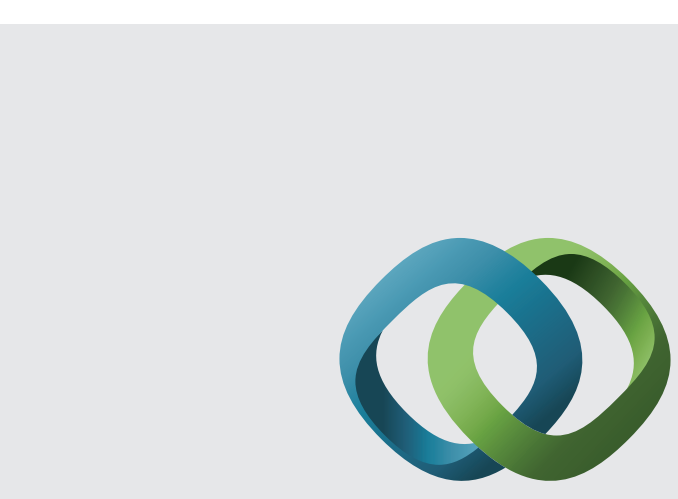

\section{Hindawi}

Submit your manuscripts at

http://www.hindawi.com
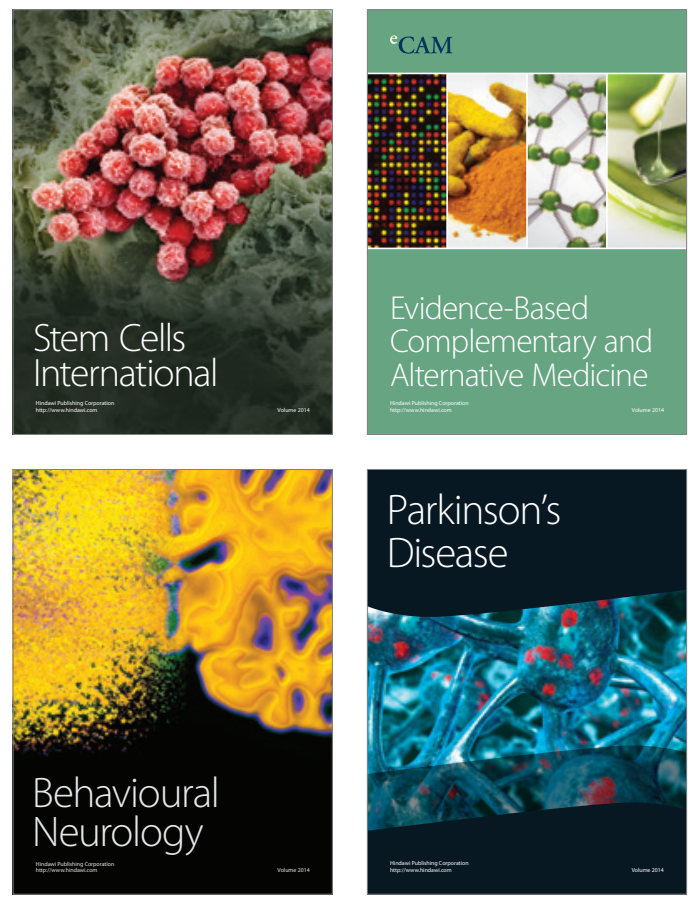
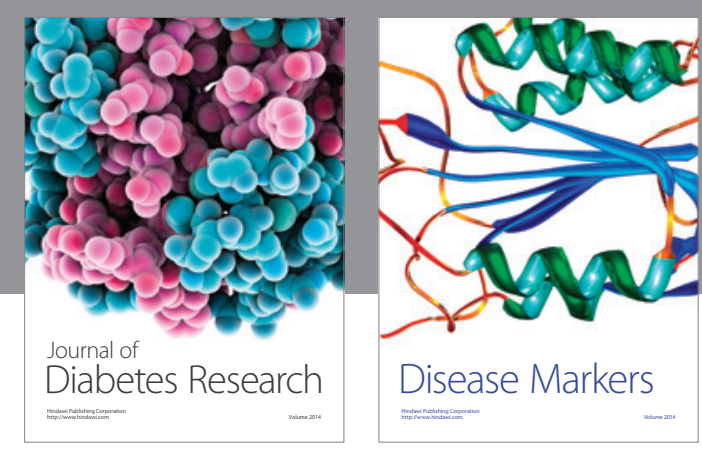

Disease Markers
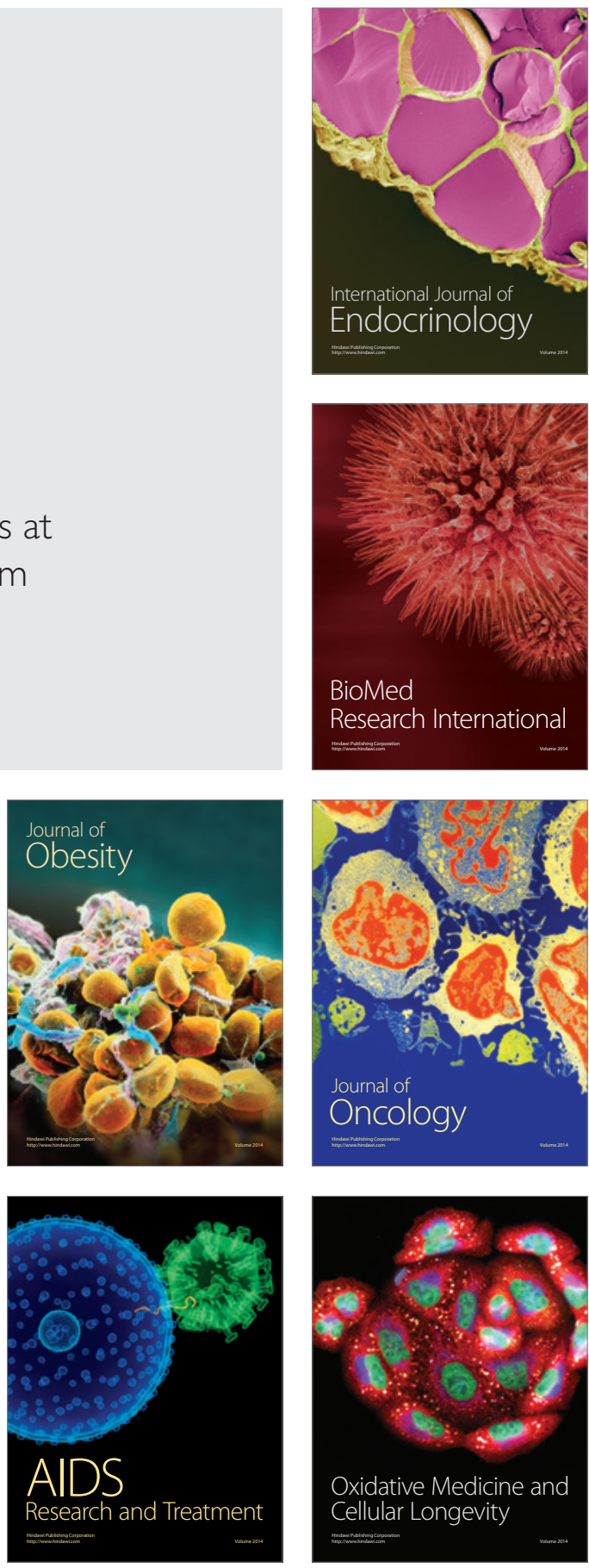